\title{
A Review on Language Learner Autonomy Research in China (2006-2016): Based on 12 Key Domestic Journals
}

\author{
Chuying $\mathrm{Ou}^{1}$ \\ ${ }^{1}$ School of English and Education, Guangdong University of Foreign Studies, Guangzhou, China \\ Correspondence: Chuying Ou, School of English and Education, Guangdong University of Foreign Studies, 178, \\ Waihuan Donglu, Guangzhou Higher Education Mega Center, Guangzhou 510006, China. Tel: 86-203-932-8036. \\ E-mail: ouchuying32@163.com
}

\author{
Received: September 2, 2017 Accepted: October 5, 2017 Online Published: October 8, 2017 \\ doi: 10.5539/elt.v10n11p76 URL: http://doi.org/10.5539/elt.v10n11p76
}

\begin{abstract}
Since the implementation of the 2001 curriculum reform and the release of the 2004 college English requirements, learner autonomy has become one of the most important research themes in the field of ELT in China, especially college English, reflecting the tendency of a learner-centered teaching approach. In this paper, I have reviewed 39 studies about language learner autonomy from 133 articles selected in key journals targeting language education published in mainland China from 2006 to 2016, so as to see what have been the features of related research through the years. In the review process, it is found that influencing factors, improving methods as well as evaluation approaches of learner autonomy have been the dominant themes that attract Chinese researchers' concern. Among them, improving methods of language learner autonomy have drawn even more attention from Chinese scholars, which have mainly addressed issues related to teachers, learner training and autonomous learning environment. It is also observed that empirical studies have been dominant through the decade and more types of students have been involved in research. However, I also note that there is still deficiency with such studies of language learner autonomy, so suggestions are provided for researchers in the field.
\end{abstract}

Keywords: China, EFL, language learning, college English, learner autonomy

\section{Introduction}

The concept of learner autonomy was first introduced into the field of language education by Henri Holec (1981), which refers to 'the ability to take charge of one's own learning' (see Benson, 2007). Across time, language learner autonomy has become a hot issue in the field of foreign language education, as more and more countries take building up students' autonomous learning ability as one of the significant goals in language teaching. A lot of studies about language learner autonomy have emerged, featuring at various topics and applying diversified research methods. The amount of related studies has reached a peak in the 1990s (e.g. P. Benson \& Voller, 1997; Dickinson \& Wenden, 1995; Gremmo \& Riley, 1995; Little, 1991; Littlewood, 1996). However, the more recent literature has witnessed "a shift towards more critical examination", and also become more qualitative (Benson, 2007). In general, there have been increasing empirical studies about language learner autonomy around the world since 2000, which mainly focus on four areas: the sociocultural meaning of learner autonomy, teacher autonomy, in-class autonomous learning and technology assisted autonomous language learning (Xu \& Zhu, 2013).

In China, "learner autonomy” is sometimes replaced by similar terms such as “autonomous learning (自主学习)” and “ability of autonomous learning (自主学习能力)". Though there are different names, it is commonly agreed among Chinese scholars that learner autonomy is a kind of ability or learning behavior with which learners self-direct their study, and this corresponds to Holec's definition. Research upon language learner autonomy in China has emerged rather late, with the first article in this field being published in 1999, but it has developed rapidly since 2004 (Yin, 2014). In CAJD (China Academic Journal Network Publishing Database), the largest Chinese academic journal database in the world, there are only 118 articles featuring at learner autonomy in foreign language education which were published before 2004. However, in a single year of 2004, nearly 140 related papers were published, with 8344 articles coming after in the following 12 years.

This research upsurge is largely related to the new round of basic education curriculum reform which was implemented in 2001. Before the curriculum reform, education in China, including foreign language education, had long been teacher-centered, in which students did not have much control over their studies and teachers were 
considered to be the only authority in the classroom. However, the 2001 reform has clearly proposed the goal of cultivating students' active learning attitude, as well as emphasizing that the teaching process should develop learner independence and autonomy (Ministry of Education, the People's Republic of China, 2001). This reform is seen as one of the most significant educational reforms in China in the $21^{\text {st }}$ century, representing a great change in terms of educational ideas and methods. The new emphasis on learner autonomy is also reflected in higher education. As regard to college English, "enhancing students' ability to study independently" was set as one of the teaching objectives in the national College English Curriculum Requirements documented in 2004 (Higher Education Division of Ministry of Education [HED, MOE], 2004). In 2007, a refined version of this requirement further demanded a change of model of instruction which should be able to strengthen learner autonomy, again suggesting its importance (HED, MOE, 2007).

As a compulsory subject for both basic education and higher education, English learning has always been important in China. It is clear that the country has already grown up to be "one of the major consumers and producers of language learning and teaching research" (X. Gao, Liao, \& Y. Li, 2013). As it is mentioned, the shift in curriculum reform towards learner autonomy just led to a huge emergence of studies about this issue in the recent 10 years. Lots of educators and researchers have conducted studies in order to learn more about learner autonomy and better promote it in China's language education context. This article, therefore, aims at carrying out a general review upon the relevant research within the past decade, thus giving readers a comprehensive understanding towards the research achievements that Chinese scholars have made in the field. To ensure the quality of articles, the selection was confined to journals listed in the China Social Sciences Citation Index (CSSCI): core journals in China which represent high-level academic achievements in terms of foreign language research. 12 journals in total were chosen in the end (see Appendix for the exact names of the journals). In these key journals, I have identified 133 articles related to language learner autonomy from 2006 to 2016, which were mostly published in Technology Enhanced Foreign Language Education (34 in total) and Foreign Language World (33 in total). I aim to highlight the dominant themes of related research in the past decade. According to the research content, these major themes are: the influencing factors of learner autonomy, approaches of achieving learner autonomy and ways of evaluating learning autonomy. Also, by going through the abstracts and methodological description of the articles, a methodological trend of related research was figured out (see Table 1). It can be seen that during the years 2006-2016, though the number of studies published is generally decreasing as time passing, empirical studies have always been dominant.

Table 1. Methodological trends (2006-2016) $(\mathrm{n}=133)$

\begin{tabular}{llll}
\hline & $2006-2009$ & $2010-2013$ & $2014-2016$ \\
\hline Theoretical research & 19 & 11 & 0 \\
Empirical studies & 47 & 34 & 22 \\
Total & 66 & 45 & 22 \\
\hline
\end{tabular}

Considering the limited space for this review, I finally decided to highlight 39 articles from these leading journals in mainland China. All the articles selected to be reviewed here have clear and comprehensive description of the methodology they used, which is likely to make the research more convincing. Then in the following content, major claims of the selected studies will be discussed in the order of the three categories, and a short summary will come after the review of each section. An overall observation of the studies reviewed will also be illustrated in the final part.

\section{A General Review on Language Learner Autonomy Research}

\subsection{The Influencing Factors of Learner Autonomy}

In the past decade, many Chinese scholars have paid effort to discover the influencing factors of learner autonomy, trying to figure out its relationship with other important educational elements, especially psychological elements. By working out such influencing factors, teachers and researchers wish to control them in order to better promote students' autonomous learning. There is a salient tendency that rather than investigating the effect of one single factor upon language learner autonomy, more researchers try to discover the relationship between it and other multiple factors. According to an earlier review carried out by Xu and Zhan (2004), there were only three representative studies which have revealed the influencing factor of learner autonomy before 2004, with all of them being single factor analysis. Though such kind of analysis still exists in the past ten years, multi-factor studies 
have won more attention generally. The following content reviews research of both streams.

\subsubsection{Single Factor Analysis}

Self-efficacy has turned out to be one of the most frequently investigated factors affecting the autonomy of English learners. Studies (Y. Chen \& J. Chen, 2007; Y. Li, 2016; P. Liu, 2014) have shown that self-efficacy is significantly positively correlated to different dimensions of learner autonomy, for example, setting up learning goals, applying learning strategies and supervising the learning process. Therefore, teachers should develop students' self-efficacy during language teaching in order to achieve greater learner autonomy. Metacognitive factor is also found to be playing an important role in developing its motivation (X. Wang, 2014) and performance (Yue \& Z. Shi, 2009). Wang's research further finds that the three aspects of metacognitive factor: metacognitive knowledge, metacognitive experience and metacognitive monitoring, tend to have different functions upon autonomous learning.

A less frequently investigated factor has been sex role, which is also claimed to be influential towards language learner autonomy (R. Zhang, 2014). According to the study, two kinds of characteristics within sex role, which are persistence and independence, have positive effect upon learner autonomy, while being shortsighted and fragile in personality can be negative to it.

\subsubsection{Multi-Factor Analysis}

Being aware of the complexity of learner autonomy, scholars in China started to study how multiple factors would affect it simultaneously. K. Li and $\mathrm{Yu}$ (2008) have analyzed the relationship between learner autonomy and three other factors: learning motivation, self-efficacy and attribution. By observing the results of the questionnaires they distributed, they find that intrinsic motivation and extrinsic motivation, together with self-efficacy, have a significantly positive correlation with learner autonomy. Among them, self-efficacy turns out to be the most influential one, followed by intrinsic motivation and extrinsic motivation. In terms of attribution, only intrinsic attribution of success is positively correlated to learner autonomy. Self-efficacy is also the research focus in the study of Wu and Q. Zhang (2009), who reveal that learner autonomy is positively correlated with self-efficacy, learning strategies and academic achievement.

More factors have been taken into consideration in the following research. Hua (2009) finds that learner autonomy is at the same time correlated with intrinsic motivation, extrinsic motivation, teachers' role, attribution and methods of autonomous learning, but has a strongest correlation with intrinsic motivation. Similarly, Xu and B. Li (2014) hold the view that multiple elements will make a difference during the learning process of language learners. They therefore try to investigate the influence brought about by five controllable factors: learning motivation, self-efficacy, learning strategies, achievement goal orientation and attribution, which include 25 variables in total. Through a questionnaire survey targeting more than 400 non-English majors, they further pick up 19 variables which are significantly correlated with learner autonomy. 5 variables finally turn out to be positive predictors of learning autonomy: meta-cognition strategies, mastery goal orientation, compensation strategies, memory strategies and information-media motivation.

It can be seen that in both single-factor analysis and multi-factor analysis, self-efficacy, learning strategies and motivation are considered to be the most important influencing factors of learner autonomy. The variety of factors analyzed in the studies suggests that researchers have become more aware of the complexity of language teaching as well as language learner autonomy, so it is necessary to take the impact of various elements into consideration when trying to develop learner autonomy. At the same time, most scholars tend to apply quantitative method to verify their supposition when doing empirical studies, becoming the trend under this research topic.

\subsection{Approaches of Achieving Learner Autonomy}

In the review process, I find that in terms of language learner autonomy, Chinese scholars are most dedicated to finding out the effective approach to achieve or improve it, and such research can be summarized into three aspects: teachers' role, learner training and learning environment.

\subsubsection{Giving Full Play to Teachers' Role}

In the past decade, how teachers can play their role more effectively in class in order to promote autonomous learning has become a research hotspot among Chinese scholars. Most researchers agree that teachers' autonomy and intervention help to ensure the implementation of language learner autonomy.

By conducting questionnaire surveys and in-depth interviews, Y. Chen (2011) proves that teacher autonomy has a positive and overall influence upon autonomy of language learners, and teachers' affective communication with students is further found out to have the greatest impact. She defines the autonomy of college English teachers as a 
kind of ability and right, with which teachers are able to regulate and control classroom teaching effectively through a series of tools or steps, and flexibly adjust the constraint upon teaching behavior from outer environment. Another researcher Lin (2015) innovatively carried out an action research which further provides evidence for the significance of teachers' intervention. Her research highlights the importance of reflective teaching and action research, in which teachers can actively participate in activities that foster learner autonomy, and make appropriate decisions according to the needs of students when difficulties emerge.

Scholars have also pointed out the specific roles teachers should play during students' autonomous learning process. Huang and Benson (2007) summarize six types of teachers' abilities from previous studies, including bridging, promoting, scaffolding, negotiating and dialoguing, mediating as well as criticizing. Taking the environment of web-based language learning into consideration, the opinion of Cao (2009) is rather similar with theirs, who also highly emphasizes teachers' role. According to Cao, these roles contain: a leader, a designer, a guider, a helper, a promoter, an evaluator as well as a supervisor. The roles and abilities mentioned above indicate that scholars are aware of the intricacy of teachers' role in promoting language learner autonomy, rather than literally interpreting the argument that "the pursuit of learner autonomy requires a shift in the role of the teacher", as Little (1995) has criticized. Then Q. Jiang (2006) proposes two main approaches of teachers' involvement in order to guarantee and enhance learner autonomy in teaching practice: active direction and prohibitive intervention. According to Jiang, this means that teachers should not only take the initiative in a series of actions which foster learner autonomy but also need to take prohibitive inventions so as to stop the inappropriate attitudes and misbehaviors. Other specific measures advocated (P. Liu \& Qin, 2007) also highlight active help, guidance and supervision from teachers.

Though research has demonstrated that teacher autonomy greatly contributes to learner autonomy, a survey which covers 116 college English teachers from five universities in China has indicated that language teachers are in general not qualified in terms of teacher autonomy (J. Gao \& Li, 2011). Specifically, they are not competent enough in adapting syllabus, making use of curriculum resources, teaching metacognitive strategies, reflecting their teaching practice and doing research. Other researchers (Xiang \& Wu, 2016) suggest that these language teachers mainly understand learner autonomy from two aspects: ability and power, and they commonly agree on the leading and guiding role of teachers during the autonomous learning process.

To summarize, researchers have made inspiring contributions about the significance and realization routes of teachers' intervention upon learner autonomy, both theoretically and practically. They have also demonstrated teachers' understanding towards different aspects of learner autonomy through surveys and interviews. What should be noticed is that whether the measures they've proposed can be popularized to more universities in China in order to improve language learner autonomy still need to be verified, and this would require more in-depth investigation in the future in order to bring about concrete and specific action lines.

\subsubsection{Carrying out learner Training Program}

Learner training, which also refers to learner development, is a way to improve learner autonomy from the perspective of learners themselves. It would not be enough for such training to make students function better just in the classroom, since true learner empowerment should contain the freedom to learn outside the teaching context and the ability to continue learning even if instruction has finished (Field, 2007). Yan (2010) investigates the longitudinal effects of a learner training program on non-English major graduate students, and manages to track the change of autonomy of both experimental and control group in two respective learning situations. Her research result indicates that such program could have positive long-term effects.

Other researchers have focused on the specific content of learning training, mainly metacognition knowledge and learning strategies, to discover the effective way of enhancing language learner autonomy.

W. Xiao, X. Wang, and Cao (2011) think highly of metacognitive knowledge, considering the cultivation of metacognitive strategy as the main channel of developing learner autonomy. Specifically, metacognitive strategy facilitates students to analyze their own learning needs and diagnose their strengths and shortcomings, thus enabling them to self-direct the process of language development. It also equips students to conduct critical reflection and assessment and become autonomous learners with aims and objectives. Their empirical study has proved that by implementing metacognitive strategies training in college English lessons, students' learner autonomy as well as English achievement could be effectively promoted. On the other hand, L. Zhang (2009) argues that metacognitive awareness training should go before metacognitive strategy training so as to help students fully realize that they are independent language learners and they have the ability to select or adapt different learning strategies according to different learning tasks. Furthermore, in the study carried out by J. Shi (2010), who divides the learner autonomy into five dimensions, metacognitive-strategy training is found to have 
different extent of influences upon those dimensions. Her empirical research gives evidence that the metacognitive-strategy training has a higher effectiveness in promoting learners' planning and self-monitoring, but has insignificant effectiveness in promoting the use of strategies, the ability of after-class learning and self-evaluating. Therefore, there is imbalanced development among different aspects of learner autonomy, and multiple ways should be combined in order to promote it comprehensively.

In terms of learning strategies, it is commonly agreed that training of learning strategies is helpful in enabling students to master skills and methods of autonomous learning, especially skills of planning, supervising and evaluating. J. Xiao and Zuo (2006) have revealed some practical methods for such strategies training so as to develop the efficiency of autonomous learning, and in their research they specifically focus on English listening. Based on the classification of learning strategies for listening proposed by O' Malley \& Chamot (1990), they compare the differences in the use of strategies between "autonomous learning class", in which students have more control over their learning process, and "classroom teaching class". What they find out is that students who are given opportunities to carry out autonomous learning apply learning strategies less frequently, especially metacognitive strategy and cognitive strategy. Such study has indicated that researchers are not only aware of the importance of learning strategies, but also how these strategies can be used with emphasis to make autonomous learning efficient.

From the review of related studies, we can see that scholars tend to believe in the positive influences of metacognitive and learning strategies in promoting language learner autonomy. However, they hold a critical attitude towards its degree of effectiveness and are trying to find better ways to implement these strategies.

\subsubsection{Building up an Autonomous Learning Environment}

It was required in the 2004 higher education curriculum reform that more English curriculum should be designed based on computer or internet, and new teaching mode should be carried out greatly facilitated by modern information technology. Also, schools should make use of the internet and multimedia in order to enable students to learn English more autonomously, with less restriction of time and space. Since then, colleges in China have been trying to discover effective methods to make use of multimedia or internet to enhance language learner autonomy. Lots of studies have emerged about how to build up an autonomous learning environment for learners with the help of such technology.

Some of the scholars paid attention to self-access language learning centers, which were established in many colleges since the reform. Self-access language centers refer to places where there are abundant resources which can provide learners with rich materials to support their learning activities, so as to meet the needs of learners of different levels, learning styles, goals and interest. It is considered to be one of the most significant ways to realize learner autonomy. However, according to Lin (2013a), who investigates the condition of such self-access centers among seven colleges, there have been concerning problems in terms of the development of language learning resources. For example, the allocation of learning resources does not suit students' needs, and they also lack an effective evaluation system to ensure their appropriateness. This research has to some extent explained why it is found that generally students have a low degree of participation and acknowledgement towards those self-access language learning centers (Tan, Zhang, \& Yan, 2011). Therefore, colleges should do more research upon learner autonomy so that they can make use of those scientific research and analysis to develop the effect and efficiency of both autonomous learning curriculum and learning resources. There should also be more financial investment so as to arouse more active teachers' participation in resources building (Lin, 2013).

However, as time passing, there are voices which decline the leading position of self-learning center. X. Jiang (2016) suggests that with the rapid development of modern technology, the construction of self-access centers should be replaced by meta-resources platform based on a U-learning (ubiquitous learning) environment, so that students can be really enabled to learn at any time and any place.

On the other hand, with the development of computers and Internet technology, computer-assisted language teaching (CALL) has been widely applied in many colleges in China. A number of researchers have performed studies about how to make full use of multimedia and internet to assist language teaching and learning for the sake of improving learner autonomy. The research focus of these studies can be divided into two mainstreams. One is the online learning and teaching platforms (L. Li \& P. Gao, 2007; Tao, 2013; Zhai \& Lv, 2016; Zhao, Shi, \& H. Wang, 2012), which also include special English websites (L. Jiang, 2006), and the other is language labs (J. Liu, 2009; H. Zhang \& Y. Wang, 2006).

To briefly conclude, researchers have brought about impressive findings in applying multimedia and internet technology in order to construct a self-learning environment for the development of learner autonomy. However, it should be noticed that most of these research turns out to be positive outcomes, with little attention paid to the 
difficulties and problems that emerged during the technology-assisted learning process. Researchers may be overly optimistic towards the prospect of learner autonomy, with insufficient recognition about its obstructive factor.

\subsection{Ways of Evaluating Learning Autonomy}

Ways of assessing and evaluating learner autonomy have also attracted much interest, and researchers attempt to develop scales so as to assess the level of autonomous learning ability scientifically and effectively. However, due to the difficulties of creating scales, just a few studies target at it and I have demonstrated some pioneering contribution here in the review. By looking through related evaluating approaches developed between 1987 and 2004, Guo and Dai (2011) find that there are mainly two kinds of methods in terms of assessment of learner autonomy. One is to take learner autonomy as a kind of ability, which can be assessed by structured self-report inventory, interviews, and teachers' comment. The other is to view learner autonomy as a kind of process or activity, which is evaluated through tactics like thinking-aloud, error detection, behavior observation, etc. So they further develop a three-dimension evaluation system which includes three basic evaluation elements: learners, teachers and environment. Based upon different variables included, this system contains 15 specific items in total, trying to comprehensively evaluate level of language learner autonomy.

Other scholars have managed to construct an evaluation system which is based on different levels of self-learning ability. $\mathrm{Hu}$ (2011) has summarized an evaluation model and scale for Chinese language learners consisting of two dimensions: subjective will and objective capability, which contain four items and eight factors. Another assessing scale is designed by Lin (2013b), who has defined learning autonomy of foreign language as the combination of ability, psychology and behavior. She later develops them into a scale for learner autonomy composed of 38 items after a rigorous process of scaling. She also suggests that we should pay attention to dynamic testing during the evaluation of learner autonomy.

In general, though there are just few studies which totally concentrate on developing approaches of assessing learner autonomy, such studies have tried their best to base their scales on a China' language learning environment, so that they can be suitable for Chinese students. They have also discovered different ways of classifying dimensions of learner autonomy and how to scientifically integrate them into the scale.

\section{Discussion}

By reviewing studies upon language learner autonomy published in leading journals of mainland China during 2006 to 2016, the research tendency of this field is figured out. The studies reviewed have generally shown a tendency of congruence in terms of research themes, and these themes reflect the issues which concern Chinese scholars most. However, among these themes, what draws even more attention along the years has been approaches of developing language learner autonomy. Researchers, who are at the same time language teachers in colleges, tend to carry out teaching experiments to testify whether the new ways of teaching could contribute to learner autonomy. Questionnaire, diaries, in-depth interviews etc. are applied together in order to collect and record students' performance and feedback, after which effective strategies are summarized so as to better promote learner autonomy in the future. In addition, related studies have featured at more types of students, which means both undergraduates and graduates, English majors and non-English majors, students in regular institutions and vocational colleges are taken as the research subjects. Last but not least, though the number of related articles published in leading Chinese journals is generally decreasing, empirical studies have become more dominant during the years. This indicates that studies engaging in empirical investigation which contain rigorous research planning, details of operational process and convincing data are more receptive than personal experiences and reflections.

Nevertheless, there have also emerged some obvious inadequacies of related research. In regard to the research outcomes, most of the studies have proved the kinds of benefits or achievements they made in cultivating language learner autonomy. However, seldom of the studies have tried to expose and investigate the various difficulties during the development of learner autonomy, as well as the hidden reasons. This to some extent suggests that Chinese researchers may be overly optimistic towards the prospect of learner autonomy, with some of the classroom practice being implemented "blindly" (D. Chen, 2006). At the same time, there is a lack of comparative as well as diachronic research. On one hand, few studies are devoted to comparing the different situations of language learner autonomy among schools at different levels, students of various majors, or individuals who have divergent learning motivation. On the other hand, related research has contributed little to the long-term developing routes of students' autonomous learning ability, which requires tracking survey. Finally, learner autonomy specifically focusing on one specific language skill, such as listening, speaking, reading and writing, has not got enough attention. Most of the studies have investigated the overall features of learner autonomy, thus ignoring the differences between individual language skills. 
It is therefore suggested that researchers pay more attention to the difficulties and obstacles appear when promoting language learner autonomy so as to fully reflect the reality of teaching practice during the process. Causes of the obstacles need to be figured out as well. Researchers could also conduct more comparative and diachronic studies, especially carry out case studies which help to reveal either the individual differences or the long-term development. They could furthermore discover whether language learner autonomy is skill-specific, which means the features of autonomy vary among different language skills. One more possible research focus is to build up a localized language autonomy theory suitable for China's foreign language teaching and learning environment, which includes structure of ability as well as ways of evaluation.

In China, English is taught as a compulsory subject both in basic education and higher education, and the teaching and learning of English is always attracting much attention and inquiry. However, it has long been criticized that English education in China is "time-consuming and inefficient" (Dai, 2001). Improving learner autonomy in language education turns out to be a significant way to change this situation. By highlighting the dominant themes of the field's ten-year research: the influencing factors, improving methods and evaluation approaches of language learner autonomy, as well as giving some suggestions for future research, this article may provide inspirations for researchers who would like to conduct relevant studies. It also helps readers who are interested in the topic understand recent development of the field, specifically regarding to English education in China. Experience in China mentioned in the review may also offer implications for countries which share similar EFL context.

\section{Conclusion}

Indeed, the large amount of articles (8344) about language learner autonomy published in China during the recent decade has indicated its great importance attached by teachers and researchers in the country. By reviewing articles selected from key journals about language education in mainland China, which represent qualified research achievements, the outstanding research themes are extracted and illustrated here in the paper. Chinese scholars have been paying much endeavor in promoting language learner autonomy, indicated by their active participation in various teaching experiments, and such experiments could have far-reaching effects upon the teacher-centered language classrooms in China. In terms of the research type, empirical studies have been dominant through the years and it would probably be dominant in the future. However, in regard to research content, researchers still need to pay more attention to the difficulties, individual differences as well as rule of development of language learner autonomy, which may deepen the studies and also broaden the research scope.

\section{Acknowledgments}

I would like to thank Dr Chen Jinshi and Dr Xiong Tao for their critiques on early drafts of this article.

\section{References}

Benson, P. (2007). Autonomy in language teaching and learning. Language Teaching, 40(1), 21-40. https://doi.org/10.1017/S0261444806003958

Benson, P., \& Voller, P. (1997). Autonomy and independence in language learning. London: Longman.

Cao, Q. (2009). Jiaoshi zai xuesheng wangluo zizhu xuexi zhong de juese dingwei [Teachers' role orientation in students' internet autonomous learning]. Foreign Language Research, (6), 174-176. https://doi.org/10.16263/j.cnki.23-1071/h.2009.06.046

Chen, D. (2006). Shilun zizhu xuexi zai woguo daxue yingyu jiaoxue zhong de dingwei [A discussion about the orientation of autonomous learning in college English teaching in China]. Foreign Language World, (3), 32-37.

Chen, Y. (2011). Jiaoshi zizhu yu xuexizhe zizhu de xiangguanxing yanjiu [A study on the correlation between teacher autonomy and learner autonomy]. Computer-assisted Foreign Language Education, (140), 55-60. https://doi.org/10.3969/j.issn.1001-5795.2011.04.010

Chen, Y., \& Chen, J. (2007). Wangluo zizhu xuexi chengji yu ziwo xiaonenggan de xiangguanxing yanjiu [A study on correlation between the achievement in web-based autonomous learning and self-efficacy]. $\begin{array}{llll}\text { Computer-assisted Foreign Language } & \text { 32-36. }\end{array}$ https://doi.org/10.3969/j.issn.1001-5795.2007.04.006

Dickinson, L., \& Wenden, A. (1995). Introduction of the special issue. System, 23(2), 149. https://doi.org/10.1016/0346-251X(95)90025-4

Field, J. (2007). Looking outwards, not inwards. ELT Journal, 61(1), 30-38. https://doi.org/10.1093/elt/ccl042 
Gao, J., \& Li, X. (2011). Zizhuxing waiyu xuexi huanjing xia de daxue yingyu jiaoshi zizhu nengli diaocha yu yanjiu [An investigation on college English teachers' autonomy within the environment of autonomous foreign language learning]. Foreign Language World, (4), 29-35.

Gao, X., Liao, Y., \& Li, Y. (2013). Empirical studies on foreign language learning and teaching in China (2008-2011): A review of selected research. Language Teaching, 47(01), 56-79. https://doi.org/10.1017/s0261444813000414

Gremmo, M.-J., \& Riley, P. (1995). Autonomy, self-direction and self access in language teaching and learning: The history of an idea. System, 23(2), 151-164. https://doi.org/10.1016/0346-251x(95)00002-2

Guo, J., \& Dai, W. (2011). Daxuesheng yingyu zizhu xuexi pingjia shizheng yanjiu [An empircal study on evaluation system of learner autonomy of college English learners]. Foreign Language World, (6), 79-87.

Higher Education Division of Ministry of Education. (2004). College English curriculum requirements (for trial implementation). Shanghai: Shanghai Foreign Language Education Press.

Higher Education Division of Ministry of Education. (2007). College English curriculum requirements Shanghai: Shanghai Foreign Language Education Press.

$\mathrm{Hu}$, J. (2011). Waiyu zizhu xuexi nengli pingjia__Jiyu er'wei moxing de liangbiao sheji [Evaluation of autonomous foreign language learning capacity: A design of a two-dimensional scale]. Foreign Language World, (4), 12-17; 35.

Hua, W. (2009). Shilun waiyu xuexi dongji yu xuexizhe zizhu. [Learner autonomy and learning motivation of foreign language]. Foreign Languages Research, (1), 57-62. https://doi.org/10.13978/j.cnki.wyyj.2009.01.024

Huang, J., \& Benson, P. (2007). Di'er yuyan jiaoyu de jiaoshi zizhuxing yanjiu [A study on L2 teacher autonomy]. Foreign Languages and Their Teaching, (12), 33-37. https://doi.org/10.13458/j.cnki.flatt.003504

Jiang, L. (2006). Jiyu yingyu zhuanti xuexi wangzhan de daxue yingyu zizhu xuexi moshi yanjiu [An investigation of autonomous learning mode of college English based on website of English subject]. Foreign Languages and Their Teaching, (3), 39-41. https://doi.org/10.13458/j.cnki.flatt.003331

Jiang, Q. (2006). Lun jiaoshi jieru xuesheneg zizhu xuexi de zhongyaoxing [The importance of teachers' intervention upon learner autonomy]. Foreign Language World, (2), 10-15.

Jiang, X. (2016). Fanzai xuexi linian xia waiyu zizhu xuexi zhongxin jianshe yanjiu-jiyu guoneiwai xiangguan yanjiu de fenxi [Constructing self-access center under u-learning environment: Analysis of relevant research at home and abroad]. Technology Enhanced Foreign Language Education, (169), 28-33.

Li, K., \& Yu, L. (2008). Daxuesheng yingyu xuexi dongji, ziwo xiaonenggan he guiyin yu zizhu xuexi xingwei de guanxi yanjiu [Relationship between college students' autonomous learnig behavior and motivation, self-efficacy and attribution]. Foreign Language Learning: Theory and Practice, (2), 1-5.

Li, L., \& Gao, P. (2007). Wangluo waiyu jiaoxue moshi xia zizhu xuexi nengli peiyang chuyi—Dalian ligong daxue yanjiusheng yingyu zizhu xuexi wangluo zaixian jiaoxue xitong xianzhuang diaocha [A discussion on learner autonomy under internet language teaching model: A survey on the use of autonomous learning system for DUT Postgraduates]. Computer-assisted Foreign Language Education, (118), 68-72. https://doi.org/10.3969/j.issn.1001-5795.2007.06.013

Li, Y. (2016). Daxuesheng yingyu zizhu xuexi nengli yu ziwo xiaonenggan de shizheng yanjiu [Empirical research on college students' English autonomous learning ability and self-efficacy]. Modern Foreign Language (Bimonthly), 39(2), 235-245, 292.

Lin, L. (2013a). Gaoxiao yuyan zizhu xuexi zhongxin de dingwei ji jianshe_-Jiyu yixiag xuexi ziyuan de diaocha. [Self-access language learning centers: Positioning and construction: A Survey on learning $\begin{array}{lllll}\text { resources]. Foreign } & \text { Languages in }\end{array}$ https://doi.org/10.13564/j.cnki.issn.1672-9382.2013.04.014

Lin, L. (2013b). Jiyu sanwei gounian de daxuesheng zizhu xuexi nengli liangbiao bianzhi yu jianyan [The construction and verification of the autonomous English learning scale (AELS): Based on a three-dimensional conceptual model of learner autonomy]. Foreign Language World, (4), 73-80; 96. 
Lin, L. (2015). Jiyu jiaoshi zhongjie xuesheng zizhu xuexi nengli fazhan de xingdong yanjiu baogao [Teachers' intervention into students' development of learner autonomy: An action research study]. Foreign Language Learning: Theory and Practice, (2), 52-59, 96.

Little, D. (1991). Autonomy: definitions, issues and problems. Dublin: Authentik.

Little, D. (1995). Learning as dialogue: The dependence of learner autonomy on teacher autonomy. System, 23(2), 175-181. https://doi.org/10.1016/0346-251X(95)00006-6

Littlewood, W. (1996). "Autonomy": An anatomy and a framework. System, 24(4), 427-435. https://doi.org/10.1016/S0346-251X(96)00039-5

Liu, J. (2009). Wangluo jiaoxue huanjing zhong yingyu zhuanye xuesheng zizhu xuexi de tansuo [Study on learner autonomy of English majors in web-based environment]. Foreign Language Research, (4), 119-122. https://doi.org/10.16263/j.cnki.23-1071/h.2009.04.027

Liu, P. (2014). Daxuesheng ziwo xiaonenggan yu yingyu xuexi zizhuxing de guanxi ji cujin duice yanjiu [The relationship between self-efficacy and learner autonomy in college English learning and countermeasures for promotion]. Computer-assisted Foreign Language Education, (158), 5-9. https://doi.org/10.3969/j.issn.1001-5795.2014.04.013

Liu, P., \& Qin, J. (2007). Jiaoshi dui wangluo huanjing xia zizhu xuexi de zhidao, jiandu yu guanli [Teachers' guide, supervision and management on web-based autonomous learning]. Computer-assisted Foreign Language Education, (118), 63-67. https://doi.org/10.3969/j.issn.1001-5795.2007.06.012

Ministry of Education, the People's Republic of China. (2001). Outline for basic education curriculum reform (for trial). Retrieved August 1, 2017, from http://old.moe.gov.cn//publicfiles/business/htmlfiles/moe/moe_309/200412/4672.html

Shi, J. (2010) Wangluo huanjing xia ligongke xuesheng zizhu xuexi nengli peiyang__yixiang jiyu yuanrenzhi celue xunlian de shizheng yanjiu [Fostering science-and-technology students autonomy in web-based learning environment: An empirical study based on metacognitive-strategy training]. Foreign Languages in China, 7(2), 63-67. https://doi.org/10.13564/j.cnki.issn.1672-9382.2010.02.010

Tan, Y., Zhang, R., \& Yan, H. (2011). Zizhu xuexi huanjing xia de xuexi celue yanjiu [An investigation into learning strategies in the self-access center for college English learning]. Foreign Language Learning: Theory and Practice, (2), 63; 64-69.

Tao, J. (2013). Jiyu jiangou zhuyi lilun xia de wangluo huanjing xia yingyu zizhu xuexi yanjiu [A study of the web environment English autonomous learning based on constructivist theory]. Foreign Languages Research, (139), 54-58, 112. https://doi.org/10.13978/j.cnki.wyyj.2013.03.017

Wang, X. (2014). Fei jingyu zhuanye xuesheng zizhu xuexi dongji yu yuanrenzhi celue de guanxi. [The relationship between metacogniton strategy and motivation of learner autonomy of non-English major $\begin{array}{lllll}\text { undergraduates]. Foreign } & \text { Language } & \text { Education, } & 35(5), & \text { 72-75. }\end{array}$ https://doi.org/10.16362/j.cnki.cn61-1023/h.2014.05.023

Wu, X., \& Zhang, Q. (2009). Yingyu zhuanye xuesheng ziwo xiaonenggan, xuexi celue, zizhu xuexi nengli yu xueye chengjiu de guanxi yanjiu [Relationship between learning achievement and self-efficacy, learning strategies and learner autonomy]. Foreign Language Education, 30(3), 43-46, 62. https://doi.org/10.16362/j.cnki.cn61-1023/h.2009.03.019

Xiang, M., \& Wu, Y. (2016). Gaoxiao Waiyu Jiaoshi Xuexizhe Zizhu Xinnian Diaocha. [An Investigation of University Foreign Language Teachers' Beliefs on Learner Autonomy]. Foreign Languages and Their Teaching, (5), 115-123, 147-148. https://doi.org/10.13458/j.cnki.flatt.004300

Xiao, J., \& Zuo, N. (2006). Wangluo duomeiti huanjing xia ruhe cong xuexicelue shang tigao tingli zizhu xuexi xiaolv [How to improve the efficiency of listening of autonomous learners through strategy training under online multimedia environment]. Computer-assisted Foreign Language Education, (109), 3-6. https://doi.org/10.3969/j.issn.1001-5795.2006.03.013

Xiao, W., Wang, X., \& Cao, Q. (2011). Peixun yuanrenzhi celue tigao xuexi zizhuxing he xuexichengji- Shizheng yanjiu [An empirical study on metacognitive strategy training used in improving learner autonomy and language achievement]. Foreign Language Research, (2), 109-113. https://doi.org/10.16263/j.cnki.23-1071/h.2011.02.024 
Xu, J., \& Li, B. (2014). Xuexizhe kekong yinsu dui daxuesheng yingyu zizhu xuexi nengli de yingxiang [Effects of EFL learner controllable factors on college students' autonomous English learning ability]. Modern Foreign Language (Bimonthly), 37(5), 647-656, 730.

Xu, J., \& Zhan, X. (2004). Guoneiwai "xuexizhe zizhu" yanjiu shuping. [Learner autonomy of home and abroad: A literature review]. Foreign Language World, (4), 2-9.

Xu, J., \& Zhu, Q. (2013). Guowai yuyan zizhu xuexi yanjiu 30 nian: Huigu yu zhanwang [A review of the research on autonomous language learning abroad]. Computer-assisted Foreign Language Education, (149), 15-20. https://doi.org/10.3969/j.issn.1001-5795.2013.01.003

Yan, L. (2010). Xuexizhe fazhan xiangmu dui yingyu Xuexi zizhuxing de changqi zuoyong yanjiu. [A study on the longitudinal effect of a learner development program on learner autonomy in English learning]. Foreign Language World, (3), 21-29.

Yin, H. (2014). Zhongguo waiyu zizhu xuexi yanjiu huigu yu zhanwang (1979-2012) [Reviews and previews on studies of autonomous foreign language learning in China (1979-2012)]. Foreign Language Education, 35(1), 66-67, 103. https://doi.org/10.16362/j.cnki.cn61-1023/h.2014.01.023

Yue, H., \& Shi, Z. (2009). Daxue yingyu zizhu xuexi yuanrenzhi shizheng yanjiu [Empirical research on College students' English autonomous learning ability and metacognition]. Foreign Languages Research, (4), 63-67. https://doi.org/10.13978/j.cnki.wyyj.2009.04.020

Zhai, L., \& Lv, L. (2016). Wangluo huanjing xia yingyu zhuanye xuesheng zizhu xuexi peiyang moshi yanjiu [Fostering learner autonomy in English majors in the network environment]. Technology Enhanced Foreign Language Education, (170), 9-14.

Zhang, H., \& Wang, Y. (2006). Duomeiti jishu zai xuesheng zizhu xuexi zhong de yingyong [A practical application with multimedia technique in foreign language learning]. Computer-assisted Foreign Language Education, (108), 74-76. https://doi.org/10.3969/j.issn.1001-5795.2006.02.015

Zhang, L. (2009). Yuanrenzhi yishi peixun—Xuexizhe zizhu xuexi nengli tigao de zhongyao qianti. [The significant premise of improving learner autonomy: Metacognitive awareness training]. Foreign Language World, (4), 56-60.

Zhang, R. (2014). Fuza lilun shijiao xia de daxuesheng yingyu zizhu xuexi nengli de yingxiang yinsu fenxi [Analysis upon English autonomous learning ability among college students within the perspective of complexity theory]. Foreign Languages Research, (2), 52-55. https://doi.org/10.13978/j.cnki.wyyj.2014.02.017

Zhao, M., Shi, X., \& Wang, H. (2012). Jiyu wangluo jiaoxue pingtai peiyang xuesheng xuexi zizhuxing de tansuo-_Yi "lingkeshi" yingyu tingshuoke kecheng sheji he shijian weili [Exploration on fostering learner autonomy on the basis of the online teaching plan_ With the course design and practice of the "nought-class-hour" English listening \& speaking as an exemplar]. Computer-assisted Foreign Language Education, (145). https://doi.org/10.3969/j.issn.1001-5795.2012.03.014 


\section{Appendix}

List of journals reviewed

\begin{tabular}{lll}
\hline No. & Chinese Name & English Name \\
\hline 1 & 解放军外国语学院学报 & Journal of PLA University of Foreign Languages \\
2 & 现代外语 & Modern Foreign Languages \\
3 & 外国语 & Journal of Foreign Languages \\
4 & 外语电化教学 & Computer-assisted Foreign Language Education / \\
& & Technology Enhanced Foreign Language Education \\
5 & 外语教学 & Foreign Language Education \\
6 & 外语教学与研究 & Foreign Language Teaching and Research \\
7 & 外语教学理论与实践 & Foreign Language Learning: Theory and Practice \\
8 & 外语界 & Foreign Language World \\
9 & 外语学刊 & Foreign Language Research \\
10 & 外语研究 & Foreign Languages Research \\
11 & 外语与外语教学 & Foreign Languages and Their Teaching \\
12 & 中国外语 & Foreign Languages in China \\
\hline
\end{tabular}

\section{Copyrights}

Copyright for this article is retained by the author(s), with first publication rights granted to the journal.

This is an open-access article distributed under the terms and conditions of the Creative Commons Attribution license (http://creativecommons.org/licenses/by/4.0/). 